Short communication:

Oedipus complex in an Antarctic fur seal pup?

Mia Wege*, Marthán N. Bester, Derek S. van der Merwe \& Martin Postma

Mammal Research Institute, Department of Zoology \& Entomology, University of Pretoria, Pretoria, Hatfield, 0083, South Africa

*To whom correspondence should be addressed:

Email: mwege@zoology.up.ac.za

\begin{abstract}
:
We present the first evidence of a possible case of the Oedipus complex in a nonprimate. An Antarctic fur seal pup, Arctocephalus gazella, unsuccessfully directed what appeared to be copulatory behaviour towards its own mother on several occasions. A herding sub-adult bull chased the pup from the female, which strengthens our suggestion that it was copulatory behaviour we witnessed. This seemed to constitute innocent sexual play with elements of the Oedipus complex rather than coercion because the female was not stressed nor did the pup possess the physical strength to coerce the female.
\end{abstract}

Total Text pages including title page: 9

Total number of figures: 3

Total pages: 8 


\section{Running Title: Oedipus complex in an Antarctic fur seal pup?}

Keywords: Oedipus complex, Antarctic fur seal, Arctocephalus gazella, sexual coercion, sexual play, Marion Island

Text:

Oedipus complex, in psychoanalytic theory, essentially is a human desire to possess the mother sexually and to exclude the father. Spiro (1994) suggests that the Oedipus complex is manifest in other primates as well. In Cotton-top tamarins (Saguinus oedipus oedipus) adult sons often mount females and even ejaculate (Ginther 2008). However, here mounting is used as a non-reproductive social tool (Ginther 2008). Due to inbreeding avoidance, the Oedipus complex is one-sided and if a female denies access to its male offspring it may lead to aggression and subsequent sexual coercion.

Sexual coercion is a common phenomenon in animals, with various theories as to why this occurs (Clutton-Brock \& Parker 1995). It is, however, agreed that sexual coercion is more prevalent in sexually dimorphic species with polygynous breeding systems such as pinnipeds (Kiyota \& Okamura 2005). Male aggression is directed not only toward females (McCann 1980; Chilvers et al. 2005; Cappozzo et al. 2008), but also toward pups (Rose et al. 1991; Kiyota \& Okamura 2005) and even heterospecifics (de Bruyn et al. 2008). The individual being coerced appears stressed, attempts to escape its current predicament (mostly unsuccessful) and is often injured or worst case, killed (CluttonBrock \& Parker 1995).

Sexual play behaviour on the other hand is a frequent occurrence amongst pinniped pups (Renouf 1991), with cases reported in several species (e.g. Bartholomew 1959; 
Wilson 1974; Kovacs 1987; Thompson 1988). Sexual play is said to increase an individual's reproductive fitness (Chau et al. 2008). Genitalia are never more than in juxtaposition and neither of the play partners appear stressed.

On 3 March 2010 at $\sim 15$ h00 a male Antarctic fur seal pup, Arctocephalus gazella, appeared to attempt mating with its mother at Trypot Beach, Marion Island $\left(46^{\circ} 52^{\prime} \mathrm{S}\right.$, $\left.37^{\circ} 51^{\prime} \mathrm{E}\right)$. ). Trypot beach is a low density rookery with approximately 42 pups counted on 7 March 2010 most of which were alone at the time because females are out at sea on foraging trips. The mother-pup pair was first identified as part of another ongoing study on $26^{\text {th }}$ of December 2009 by trained field personnel and both were consequently tagged with colour-coded and uniquely numbered flipper tags (Dalton Jumbo Rototags, Henley-on-Thames, U.K.). The pup was seen suckling from the mother on numerous occasions during daily observations which confirmed filialness. On the day in question the pup was first seen suckling from its mother (Fig. 1). The female rolled onto her back at which point the pup climbed onto her. The female then rolled onto her stomach, and the pup then performed clear hip thrusts (Fig 2a) which are characteristic of fur seal copulatory behaviour (King 1983). The female seemed unaffected by this hip-thrusting behaviour at first. Pelvic movements became more vigorous and after three minutes the female rolled over, the action which threw the pup off. It is unknown whether the pup had extended its penis. The pup started suckling again for 30 seconds after which it mounted the female for the second time. Pelvic thrusting continued for a minute before the pup stopped this action spontaneously and started to suckle again for five minutes. Both female and pup fell asleep after the pup finished suckling. Another 15 minutes passed with both individuals sleeping before the observation was terminated. 
On the $6^{\text {th }}$ of March the same pup was again seen hip-thrusting on top of its mother. At $15 \mathrm{~h} 39$ the pup was suckling from the female and then mounted her again. However, this time the female immediately threw the pup off. The pup started suckling again and after a few minutes fell asleep. At $16 \mathrm{~h} 24$ the pup climbed on top of the female's back and started thrusting its hips once again for a few seconds until it was interrupted by a young adult bull that chased the pup from the female. The next morning (7 March 2010) at $\sim 7$ h40 the pup was once again on top of its mother performing copulatory pelvic movements for approximately two minutes (Fig 2b). This time the observer accidentally disturbed the female which ran off and then reunited with her pup a few minutes later to nurse.

The pup was approximately 90 days old at the time (median pupping date on Marion Island is between 5 and 7 December (Hofmeyr et al. 2007)). In Antarctic fur seals lactation lasts for approximately 110 days and males reach sexual maturity at 3-4 years of age (Payne 1979).

Although the observers never could see an extended penis, we suggest that this was copulatory behaviour because the pup mounted the female, the genitalia were in juxtaposition and he performed clear bouts of the characteristic pelvic thrusting, alternating its speed of thrusting (King 1983). Conversely, our failure to observe the extension of penis (and insertion and ejaculation) suggests it might simply have been play behaviour. However, the bull that chased the pup off might also indicate that it recognised the pup's actions as copulatory behaviour. Closely related Subantarctic fur seal (Arctocephalus tropicalis) bulls show a second reactivation of testes and an increase in testosterone levels during the moult (March to April; Bester 1990), and it is 
likely to be the case for $A$. gazella as well. In both species younger bulls again become aggressive after the breeding season, they chase away other bulls and herd or attempt to herd females and pups, preventing them from running off (Bonner 1968; Bester 1977).

These younger bulls that herd females might also have assumed the "father-role" from the pup's perspective. Oedipus complex is not only the desire for the mother but also a 'hatred' for the father. Antarctic fur seals are polygynous breeders with no paternal care (Hoffman et al. 2003). This means that females have no permanent consorts to fulfil this paternal role. Despite this, Spiro (1994) suggests that the Oedipus complex could still apply to such an animal society. In certain primate species direct rivalry between the male offspring and father exists, whether they are monogamous breeders (e.g. the whitehanded gibbon Hylobates larr - Carpenter 1940) or polygynous breeders (e.g. hamadryas baboons Papio hamadryas - Kummer 1968; Spiro 1994). In the case of polygynous breeders it is not the father per se but rather a father-like figure or alloparenting males e.g. cotton-top tamarins (Ginther 2008) or simply a male showing sexual interest in the female (Spiro 1994) such as the young bulls herding females during the moulting season (Bonner 1968). On the other hand, Oedipus complex is a concept related to Freud's psychosexual development theory with recent observations in the behavioural and neurosciences raising questions about the ubiquity of the Oedipus complex as well as about its significance for psychological development (see Friedman \& Downey 2002).

We suggest that the male pup that was apparently attempting to copulate with its mother possibly exhibited the Oedipus complex in the form of innocent play rather than sexual coercion. The female never seemed stressed, unlike during sexual coercion, but 
appeared mostly unaffected. Furthermore, twice daily observations lasting on average two hours per observation have been performed at Trypot beach since January 2003. Regardless, never before has such behaviour been observed. Despite countless hours of observations in other pinniped species across the world, sexual coercion of adult females by pups has never been observed (e.g. Kovacs 1987; Opzeeland et al. 2009). Physically the pup in the present study is simply too small (9.5. $\mathrm{kg}$ on 7 March 2010 at $\sim 90$ days of age) to exert any control over its mother (39 kg on 26 December 2009). Furthermore, play behaviour is most common in juvenile, male individuals, of good body condition and in an environment with little or no stress (Oliveira et al. 2010), a situation exemplified by the 'Oedipus' pup (this study). However, that the male pup chose to direct this type of play behaviour at its own mother, suggests an element of the Oedipus complex. We argue this because sexual play behaviour is common in juveniles but have never before been seen directed at an individual's own mother.

\section{Acknowledgements:}

The Department of Environmental Affairs provided logistic support within the South African National Antarctic Programme. The Department of Science and Technology, through the National Research Foundation (South Africa), provided financial support. We thank the anonymous reviewers for their pertinent comments.

\section{Literature Cited:}

Bartholomew GA (1959) Mother-young relations and the maturation of pup behaviour in the Alaska fur seal. Anim Behav 7: 163-171. 
Bester MN (1977) Habitat selection, seasonal population changes and behaviour of the Amsterdam Island fur seal Arctocephalus tropicalis on Gough Island. D.Sc. Thesis, University of Pretoria $193 \mathrm{pp}$.

Bester MN (1990) Reproduction in the male sub-Antarctic fur seal Arctocephalus tropicalis. J Zool (London) 222: 177-185.

Bonner WN (1968). The fur seal of South Georgia. British Antarctic Survey Scientific Reports 56: 65.

Cappozzo HL, Túnez JI, Cassini, MH (2008) Sexual harassment and female gregariousness in the South American sea lion, Otaria flavescens. Naturwissenschaften 95: 625-630.

Chilvers BL, Robertson BC, Wilkinson IS, Duignan PJ, Gemmel, NJ (2005) Male harassment of female New Zealand sea lions, Phocarctos hookeri: mortality, injury, and harassment avoidance. Can J Zool 83: 642-648.

Chau MJ, Stone AI, Mendoza SP, Bales KJ (2008) Is play behaviour sexually dimorphic in Monogamous species? Ethology 114: 989-998.

Clutton-Brock TH, Parker GA (1995) Sexual coercion in animal societies. Anim Behav 49: $1345-1365$.

De Bruyn PJN, Tosh CA, Bester MN (2008) Sexual harassment of a king penguin by an Antarctic fur seal. J Ethol 26: 295-297.

Friedman RC, Downey JI (2002) Sexual orientation and psychodynamic psychotherapy: sexual science and clinical practice. Columbia University Press, New York.

Ginther AJ (2008) Reproductive biology and social strategies of cooperatively breeding adult male cotton-top tamarins (Saguinus oedipus oedipus) in two life-history phases: fathers and adult sons. PHD thesis, University of Wisconsin-Madison, Wisconsin, United States of America. 
Hoffman JI, Boyd IL, Amos W (2003) Male reproductive strategy and the importance of maternal status in the Antarctic fur seal Arctocephalus gazella. Evolution 57: 1917-1930.

Hofmeyr GJG, Bester MN, Pistorius PA, Mulaudzi TW, de Bruyn PJN, Ramunasi JA, Tshithabane HN, McIntyre T, Radzilani, PM (2007) Median pupping date, pup mortality and sex ratio of fur seals at Marion Island. S Afr J Wild Res 37: 1-8.

King JE (1983) Seals of the world. Oxford University Press, Oxford.

Kiyota M, Okamura H (2005) Harassment, abduction and mortality of pups by nonterritorial male northern fur seals. J Mammal 86: 1227-1236.

Kovacs KM (1987) Maternal behaviour and early behavioural ontogeny of harp seals, Phoca groenlandica. Anim Behav 35: 844-855.

Oliveira AFS, Rossi AO, Silva LFR, Lau MC, Barreto RE (2010) Play behaviour in nonhuman animals and the animal welfare issue. J Ethol 28: 1-5.

Payne MR (1979) Growth in the Antarctic fur seal Arctocephalus gazella. J. Zool. Lond. 187: 1-20.

Renouf D (1991) The behaviour of pinnipeds. Cambridge University Press, Cambridge Rose NA, Deutch CJ, Le Boeuf BJ (1991) Sexual behavior of male northern elephant seals: III. The mounting of weaned pups. Behaviour 119: 171-192.

Spiro ME (1994) Culture and human nature. Kilborne B, Langness LL (eds.) Transaction Publishers, New Jersey.

Thompson PM (1988) Timing of mating in the common seal (Phoca vitulina). Mamm Rev 18: 105-112.

Wilson S (1974) Juvenile play of the common seal Phoca vitulina vitulina with comparative notes on the Grey Seal Halichoerus grypus. Behaviour 48: 37-60. 
Figure legends:

Fig. 1. The male Antarctic fur seal pup (Arctocephalus gazella) suckling from it mother. Photo: M. Wege

Fig. 2a. The male Antarctic fur seal pup (Arctocephalus gazella) attempting to mate with its own mother. Photo: M. Wege

Fig. 2b. The male Antarctic fur seal pup (Arctocephalus gazella) attempting to mate with its own mother. Photo: D. S. van der Merwe 


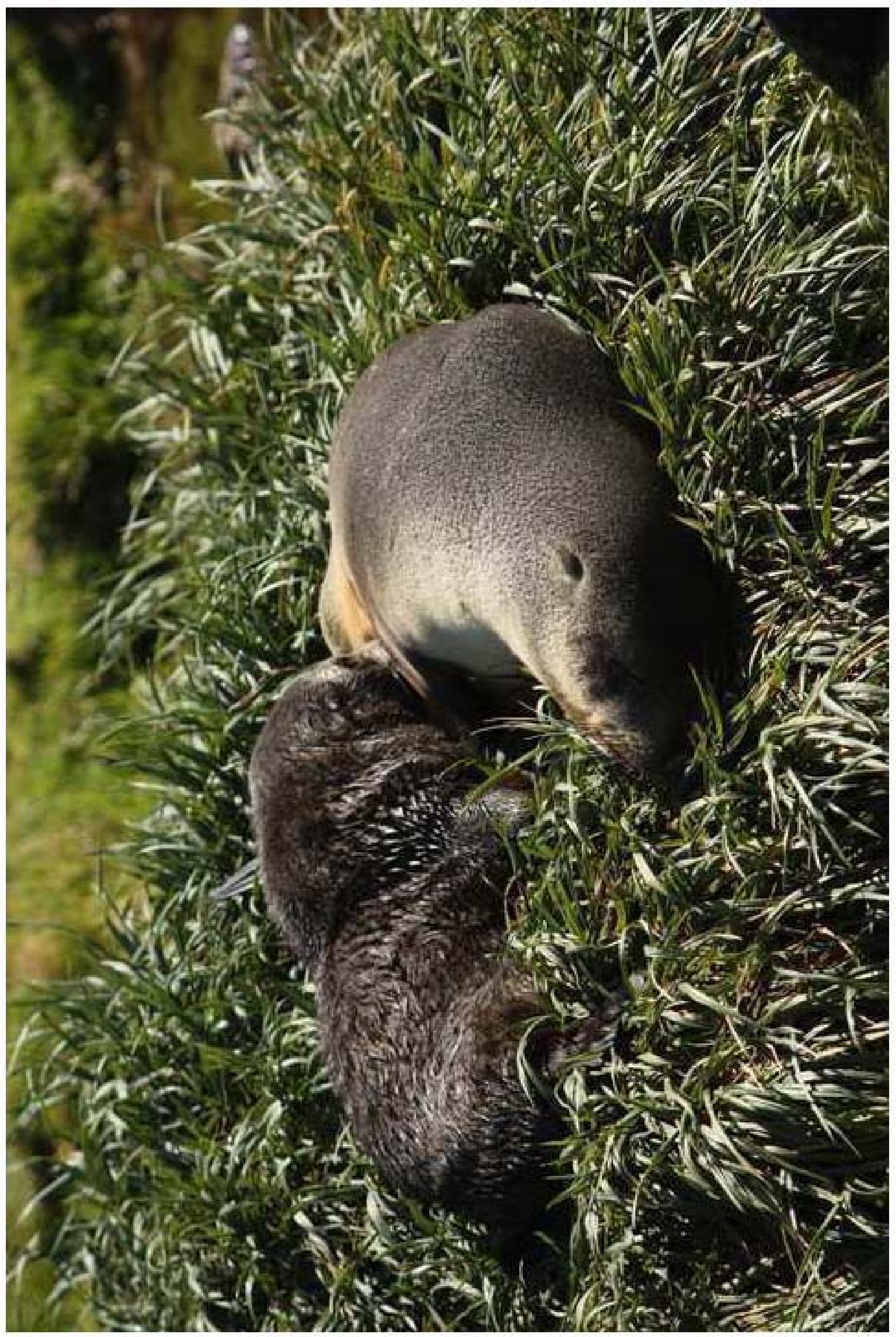




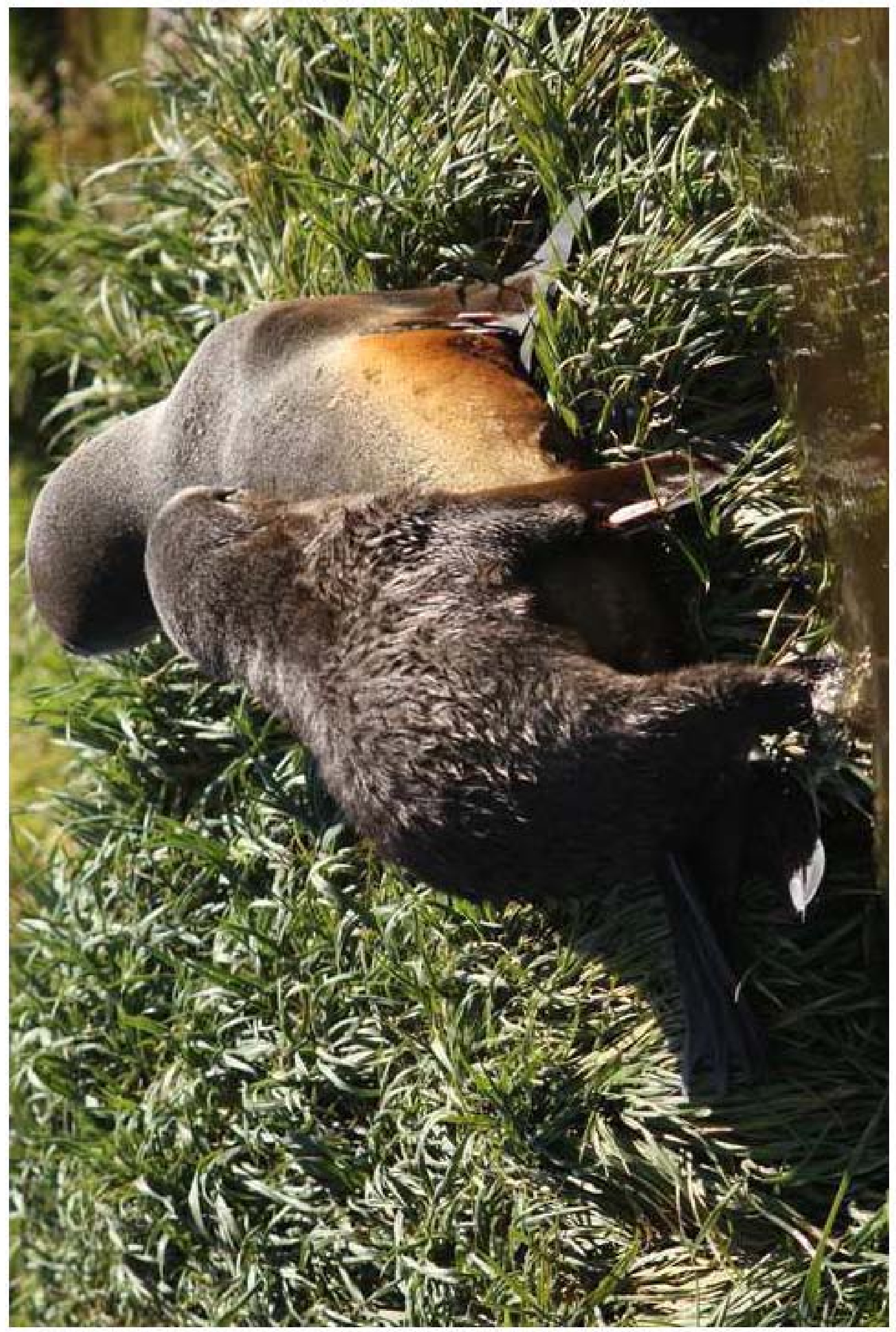




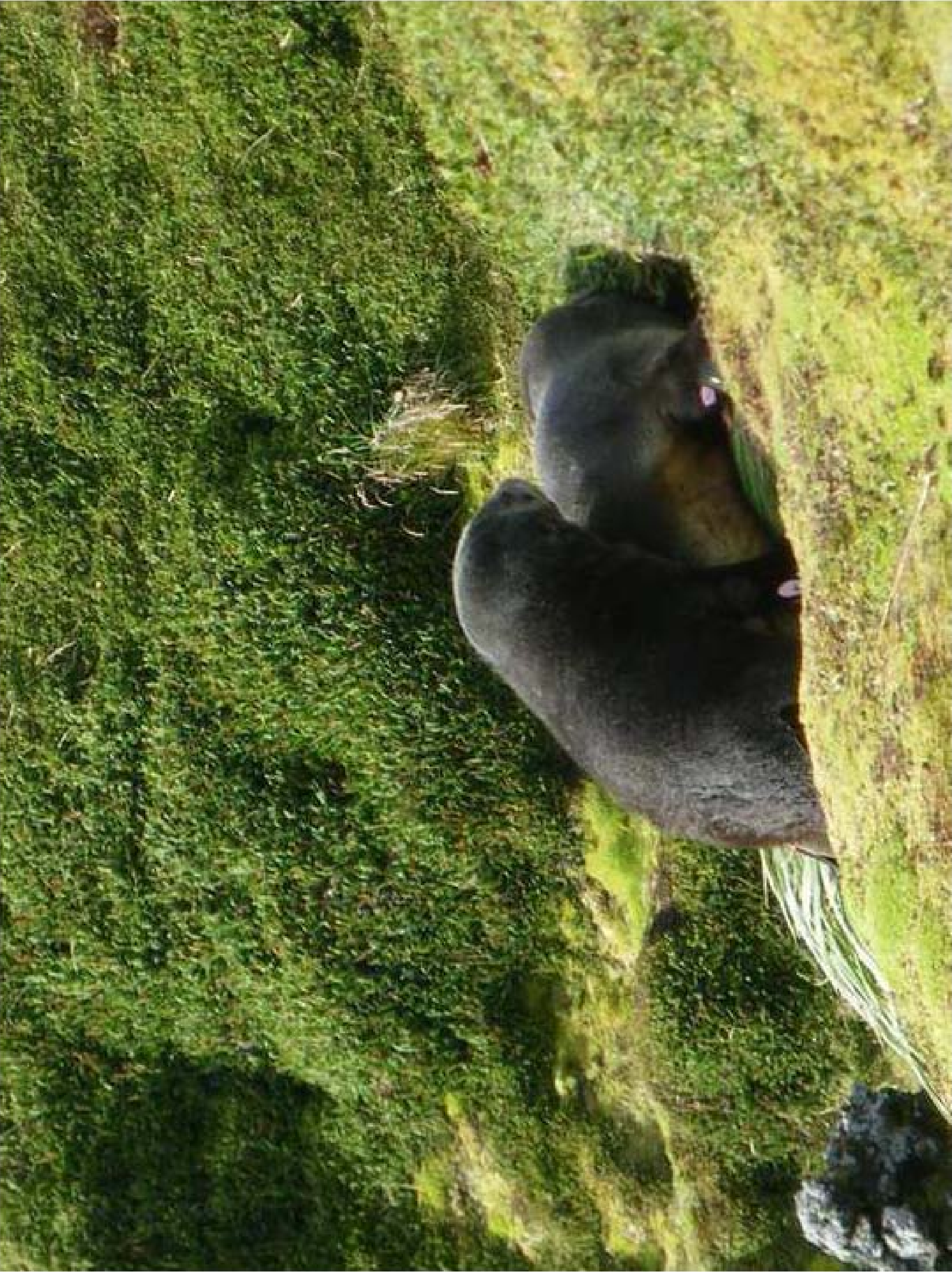

